\title{
Cognitive Reflections on the Fragment-based Design for the Online Course of Chinese Menglong Poetry
}

\author{
Zhong Deng \\ School of Foreign Languages \\ Hunan University \\ Changsha, China
}

\begin{abstract}
Particle" or "fragment" is one of the key notions for the ongoing fever of online courses design and management. However, hidden behind the wide adoption of the practice of delineating the course contents into separated "fragments" lies voices of disagreement and refutations. This article, accordingly, is intended to address one of the most controversial issues in this regard, namely, the nature of "fragment" and the mechanisms that account for the its applications. By taking the online course of Chinese Menglong Poetry (or Misty Poetry) the author is experimenting with at a China's university, this article draws a tentative conclusion that the notion of "fragment" is innately semantically complex and any simplistic approach is likely to end up in misinterpretation and misconduct in terms of how an academically rigorous course is to be constructed online.
\end{abstract}

Keywords-fragment; online course of Chinese Menglong Poetry; continuum; conceptualization

\section{INTRODUCTION}

The recent decades have witnessed an increasing fever in many China's colleges and universities that top-quality and highly popular courses have been transformed into online programs in a bid to attract and benefit potential learners across the country who do not have the access to university-level studies or who are interested in such courses for the sake of personal or career development. Empowered by the Internet and video clips that are created for online courses, far more people in China are involved in learning what they may otherwise not granted opportunities to learn, and accordingly, their comparatively undesirable status in terms of the knowledge foundation and of the adeptness of grasping the course contents poses a challenge to the course designers. Thus, as to how to make the course contents more accessible and better comprehensible, several moves have been initiated, many of which modeled on the prevalent practices in Europe and the US. Among the measures that are widely used or strongly recommended, the fragmentation of the course contents into distinctive parts, or "particles", is one of the most endorsed methods, signalizing the simplification and crystallization of the originally "bulky" and "integrated" entity of courses.[1] "Particle" as the result of fragmentation in such a context sends a metaphorical message that online courses are essentially learner-friendly, and implies a somewhat vague promise that all of the learners can understand and catch up with what the course is intended to deliver.

\section{Challenges to The COMMON PRACTICE OF CREATing "FRAGMENTS"}

However, not all teachers and scholars believe fragmentation is the way for the future. There is one major and consistent rebuttal. Namely, how should be the boundary of each of the fragments (as a well-established category) satisfactorily defined? [2] This refutation is voiced because 1) technically, if a fragment is to be constructed, a boundary is needed in order to distinguish this fragment from that one and 2) for any fragment; a stable inner structure or framework is desired in order to make sure it stands as a physically definable entity. Here comes a problem if a fragment is to be in line with the two criteria just mentioned. For one thing, the notion of "boundary" is to some degree misleading as recent studies on human cognition and categorization have clearly shown that it is not always easy nor convincing to set up a clear boundary between objects.[3] For example, the boundaries between a wide range of similar colors are not universally definite and stable: "red" in the eyes of some people is not necessarily the "red" in the eyes of others (who may say it is "slight red" or "scarlet") and the distinction between so many of versions of "reds" are not possibly there to be academically located.[4] Thus, the same principle is also true of the fragments, meaning that a reasonable doubt should be cast on the clear-cut boundary between fragments and a thorough investigation should be conducted into the nature of "fragments" in an attempt to justify the creation of "boundaries". For another thing, as to the relations between fragments and the course contents as a whole, it will be dangerous to consider that the "whole" is simply or mechanically made up of the "fragments" (or vice versa). This is because the current research on cognitive gestalt and its underlying mechanisms for humans to look at the part-whole relations of objects have proved that people have developed a psychologically programmed habit to view whatever things that confront them from a wholenessoriented/superior point of view. More specifically, empirical studies show that humans do not tend to work on the individually separated parts until they get to know what the whole picture looks like.[5] It is obvious that the particle- or fragment-based design for online courses fails to address this 
problem and it is why further explorations should be called upon.

\section{A CASE Study OF THE ONLINE COURSE OF CHINESE MENGLONG POETRY}

In this chapter we intend to demonstrate how the fragmentbased design of online courses may get stuck in trouble though in general this design method is competent for a quality online program. We look at the online course of Chinese Menglong Poetry for two reasons. Firstly, this course is qualified as an online course in terms of the unabated popularity of Chinese Menglong Poetry among young people even today. As a highly distinguished genre of modern poetry in China, Menglong Poetry (The Chinese word Menglong means the obscurity and indirectness of such poems which were created from the 1980s and 1990s) caters to the need of many as it is deeply interwined with the brand-new aesthetic and philosophical pursuits of young people around 40 years ago when China has just stepped out of an unprecedented social and political chaos. There is not any other genre of poems in modern Chinese literature that matches the Menglong poetry as a symbolic milestone in relation to the historical influences and literary innovations. Secondly, this course is by nature not so much concerned with concrete and presentable knowledge points as it is with subjectively-oriented capabilities on the part of learners to understand, appreciate and comment on the poems. This objective seems relatively challenging for an online course at the first glance because it is widely assumed that poems, especially modern poems, are so subjectively constructed that very few people can really make sense of them. We, on the contrary, disagree with this point because we believe a cognitive approach is likely to lead us to desired findings as to how Chinese Menglong Poetry can be analyzed in a way other than the established ones.

\section{A. Initial Course Contents of Chinese Menglong Poetry}

According to our initial plan, the online course of Chinese Menglong Poetry consists of three major parts: the historical background, representative poets and their poems, comments on Chinese Menglong Poetry. The three parts are to be arranged into three units respectively, each of which is further arranged into smaller topics. Actually, this is a typical means to deal with courses on literature in China's colleges and universities and for a long time it has seldom been questioned. More importantly, this arrangement is satisfactorily suitable for online programs because all the content is to be fragmented into "particles". For example, in the unit of "renowned poets", we can easily place many a poet into our sub-units such as Bei Dao, Mang Ke, Gu Cheng and so forth. Under the name of the poets, as the word "particle" semantically suggests, we can make more specific slots for such points of knowledge as their respective life experience, love affairs and marriages, education background, etc. Similarly, in the units of "writing styles", we can as well make a lengthy list of sub-units including "romantic", “imaginative”, "self-constrained", to name but a few, all of which are subjected to further categorization.

Hierarchical and easily accessible as the design is both teachers and students in the initial pilot program have reported their concerns. For teachers, the most frequent comment we have received is about the alienation or absence of the role of the teachers themselves in making the video clips. In other words, the role of a teacher seems to be transformed into one of a "tour guide" because what he or she is supposed to do in the fragment-based design is to introduce facts and figures concerned with the points of knowledge of each slot, a task on the level of informing the receptors of "what", but not of explaining them "why" and "how". Obviously, this is not what a high quality teaching design should be about. For students, not surprisingly, the most concentrated complaint is that they are not really attracted by the clips, nor can they possibly benefit substantially from the clips. Their reasoning is that, as the clips are heavily concerned with facts and figures of the Menglong Poetry, they may as well visit the related resources on the Internet to access what they want to know. So in this case, what is the point in arranging online courses for them? Besides, some students seemed to be skeptical about the limited length of the video clips, considering it may deprive both the teachers and students of their due patience to touch upon more relevant details and illustrations.

On the whole, our initial design of the course contents did not work well. This drove us to re-consider the inefficiency and inadequacy of the fragment-based design and we did achieve better when taking a cognitive approach to both Chinese Menglong Poetry and the course design mechanisms.

\section{B. A Cognitive Look at Chinese Menglong Poetry as an Online Course}

To some degree, Chinese Menglong Poetry is among the most frequently and profoundly discussed literary achievements in China. However, if taken as a course designed for majors in language and literature, Menglong Poetry needs more scholarly attention in light of the effectiveness and quality of course design. Empowered by the recent development of cognitive linguistics and cognitive poetics, [6]we believe that Chinese Menglong Poetry is well analyzable and interpretable as a quality online literary course innately demands.

Firstly, the sense of "continuum" valued by cognitive linguistics serves as an ideal perspective to explore the nature of Chinese Menglong Poetry. In linguistics, "continuum" is derived from a cognitive interpretation of grammar and meaning, which, going against the prevalent Chomskyan view point, asserts that there is not any tangible and necessary boundary between the grammar and meaning in language. Instead, grammar and meaning exist in a continuously extendable dimension in which the differences between the two are merely true in degree of complexity. [7] Putting this notion into the study of the nature of Chinese Menglong Poetry, we find out a similar scenario where the grammar and meaning of the poetic language also exist in a continuum. For example, in Bei Dao's "Answers", there is a remarkable pattern of repetition of the structure "I don't believe...". Many studies in the past simply viewed this as an unconventional use of rhetoric device of parallelism instead of trying to link it with a possible expression of usual meaning. Thus, in many traditional literary classes, this linguistic fact is more often than not discussed as a grammatical choice of the poet and as a piece of evidence to demonstrate a novel writing style. In a 
sense, the traditional teaching pattern of isolating grammar from its potential of expressing an undetected or unclarified meaning has served as a pedagogical foundation for the fragmentation in online course design.

Secondly, the notion of "conceptualization" strongly advocated by cognitive linguistics and cognitive poetics works as an essential epistemological instrument for the elaboration of Chinese Menglong Poetry. "Conceptualization” itself is by no means a novel idea, but, it is often understood simplistically as a process of extracting "concepts" from the concrete beings in the world. However, conceptualization is about how humans see the world, real and experiential, and elicit systematic perceptions and knowledge from it. For example, when going somewhere from where he lives, a man does not always bring a map with him for directions; what tends to happen instead is that he is navigated by a conceptualized map which is not necessarily as detailed and precise as an authentic one but made of various concepts he has developed and accepted during the previous experience of walking there. In this sense, this "map" is internally built and working as an entry of the corpus of knowledge, with reference to what is externally there in the real world but turning on an subjective look by means of integration, categorization, localization and many other cognitive operations.[8] Therefore, if we apply the sense of conceptualization to our investigation of Chinese Menglong Poetry, we can also be expected to figure out a species of conceptualization that works throughout the continuum between grammar and meaning. Namely, according to the basic assertions of cognitive linguistics, grammatical structures in Chinese Menglong Poetry are in line with the conceptualization of time, space, and many other important dimensions people have been interacting with in life, [9] this means grammatical structures can be regarded as sharing the identical structures of such real-world dimensions, or at least having something in common. Similarly, meaning is also a representation of such a species of conceptualization, signifying how concepts work in a specific structure so as to be captured and understood by a speech community. Hence, it is manifest that the notion of conceptualization serves a cognitive bridge that links the real world with the linguistic facts in the poems. Unfortunately, previous discussions of Chinese Menglong Poetry have to a large degree ignored or minimized such a linkage, thus, as we can see in the case of the design of the online course, underlying the common practice of fragmentation as well.

\section{A Possibly Better Course Design for Chinese Menglong Poetry}

By understanding and accepting the cognitively-based assertions of "continuum" and "conceptualization" discussed above, we now have an encouraging prospect of offering a better course design for Chinese Menglong Poetry that well counters the weakness of the fragment-based design. For the purpose of clarity, it is important to state that we do not mean to overthrow the fragment-based approach completely but intend to make a better interpretation of the term "fragment" or "particle" in an attempt improve the overall quality of this online course.

In trying to make this happen, we resort to a simple pattern of comparison between the two models of course design. First, as the initial pilot design suggests, we fragment the course contents into "particles" with clearly seen boundaries. Take the unit "writing styles" as an example, we initially came up with 1) the interpretation of styles and 2) the introduction to the major styles as the core contents. Beneath this level, there were subcategorizations of a range of recognized styles and poems written in such styles respectively. By contrast, our new design made a special effort of highlighting the sense of "continuum" in both of the two contents. In the first content (Interpretation of styles), we put enhanced emphasis on illustrating the continuum between word/sentence structures, meaning and literary effects. An introductory paragraph reads:

"Style is desirably understood as both a literary and linguistic term with meaning mediating in between that links the two into an integrated perspective to look at how a poem renders what the poet intended to express. You should know two things before you try to intellectually and aesthetically interact with Chinese Menglong Poetry: 1) Any style is substantiated by words, phrases and grammatical structures which are all meaningful. 2) Any style is existentially associated with the intended meaning of the poet, which is embodied in his or her language-level choices represented in the poem."

This paragraph aims to help the learners develop a holistic approach to Chinese Menglong Poetry rather than separating language facts, meaning and literary concerns into isolated clusters of points of knowledge. Also, this paragraph liberates the teacher from the role of merely being a "tour guide" as he or she now has an important obligation to "explain", to "clarify" and to "enlighten" rather than to simply "introduce". Accordingly, students are expected to be more attentively involved in the program as they are given thought-provoking ideas or speculations to weigh and digest as part of a highly cognitively beneficial course.

Moving onto the second content (Introduction to the major styles), we provide a non-fragment design as well. Here, what concerns us most is the question: Are there always definable boundaries between styles? As is mentioned in the second chapter, the sense of "boundary" does not always stand from a cognitive perspective. Therefore, in terms of styles of different Chinese modern poems, the practice of setting up a clear-cut boundary is well questionable. For example, the romantic style is usually characterized by the genuine and uncontrollable release of emotions and sentiments of the poet, but the question is that in other poems which are not labeled as romantic, expressions of emotions is also the case. Likewise, the naturalistic style is reputable for its inclination to reproduce images that resemble what is naturally beautiful such as mountains, rivers and forests. But again there is a problem in labeling those so-called non-naturalistic poems which do also contain elements highlighting resemblances to natural landscapes. In a word, to clearly or unambiguously state the distinctions between different styles is in a sense impossible in that a style is not abruptly mutated into another, nor is a style automatically isolated from another. Upon such an understanding, we do not display in our video clips what these styles are about respectively, but make the clips more interactive by raising questions such as "Is Style A similar with Style B?", "How do you interpret the similarities and 
differences between Style A and Style B?" and "Do you think it is reasonable enough to make an absolute distinction between the two styles?" We make these questions a part of the quiz and assignments, and ask the teachers to provide some preliminary answers in the clips beforehand, with the aim to driving the students to think about the sense of "continuum" and "boundary" in association with their own reading experience.

Next, in order to incorporate the sense of "conceptualization" into our new course design, similarly, we conduct a comparison as we did for the notion of "continuum". In our initial plan where fragmentation played a central role, we did not provide a logical line starting from the analysis of language facts and eventually arriving at the discussion of literary effects. In other words, language facts and literary effects were two "particles" in the design isolated from each other. What is problematic about this design, as the second chapter suggests, is that students were not be able to make the linkage themselves, resulting in "knowing" the unconventional language facts and the unusual literary facts as two points of knowledge individually. Some of the students were bored of such fragmented displays of knowledge; others, on the other hand, who might be curious about how literary effects are realized did not get any clue in the design.

By comparison, our new design focuses on the role of conceptualization in connecting the domain of language with that of literary interpretation. When making the clip on $\mathrm{Gu}$ Cheng's poems, for example, we offer such a 20-minute design:

- Step 1: Providing several lines of the most reputable poems by Gu Cheng in the first 2 minutes of the clip with two questions: 1) Do you think Gu Cheng's language is beautiful or poetic? 2) Do you think the literary images and implications in these lines are beautiful or poetic?

- $\quad$ Step 2: Providing the teacher's elaboration (5 minutes) on the linkage between language facts and literary effects, which involves two parts: 1) how language form is related to meaning and 2) how meaning is associated with the intention of the poet. This illustration seems to be very theoretical, so quite a few examples are given.

- $\quad$ Step 3: Providing Gu Cheng's own comments on and explanations of his language choices and literary pursuits (5 minutes). Such materials are abundant in the publications in the 1980s and the 1990s. We pay much attention to the implicit linkage alluded in his remarks between what he intended to achieve in his poems and why he wrote the way as he poems demonstrated.

- Step 4: Providing the teacher's elaborations on the remarks of $\mathrm{Gu}$ Cheng (8 minutes). The teacher's talk consists of two parts: 1) interpreting $\mathrm{Gu}$ Cheng's remarks by accentuating the process how language choices can assist in the realization of literary effects; 2) leading the students to think about whether Gu Cheng's remarks make sense.

It is presumably clear that this design is superior to the fragment-based one. The first reason is that it provokes the shared mechanisms of conceptualization among the readers, on line learners, in this case. The point is that, in this design, a poem is not detached from its physical dimension which is configured by various language choices adopted by the poet, nor is it alienated from its psychological dimension which is repres0ented in different degrees of literary effects perceived by both readers and critics. What integrates the two dimensions is the conceptualization mechanisms shared by all members of a speech community, which underly both the language choices (as cognitive linguistics usually explains) and the literary considerations (as cognitive poetics accounts for). Another reason is that by clinging to the shared mechanisms of conceptualization, this design allows the teachers and students to be engaged in the same cognitive exploration of how a poem is supposed to be comprehended and appreciated on the basis of interrelated considerations of language, meaning and literary effects in a row. This pattern, in this way, figures out connections out of what are originally disconnected, thus bringing about new sense of vitality to the teaching and learning activities of Chinese Menglong Poetry.

\section{CONCLUSION}

Based on the two cognitive concerns discussed above, we feel obliged to state that the fragment-based design for online courses is sometimes problematic when it is used for subjectivity- and capabilities-oriented courses such as Chinese Menglong Poetry. In order to solve the problems, we ought to clarify the meaning "fragment" by not only embracing its semantic elements in relation to separation or isolation, but also exploring the justification in recognizing the logical connections in between if the notion on its own is to stand. More importantly, it is high time to address the relations between knowledge and ability by working on the possible interface between these two domains. In other words, for a given "fragment", it is not possible that it involves elements of knowledge alone or of abilities alone. On the contrary, these two areas of intellectual products of humans are integrated in some way that the current fashion of setting up fragments" does not fully comprehend. Therefore, "fragments" should be seen more holistically and employed more meticulously before they are to function well as expected in the design of online courses.

\section{REFERENCES}

[1] J.V.Bruggen, "Theory and practice of online learning," British Journal of Educational Technology, 2005, 36(1), pp.111-112.

[2] H. Siegel, “Critical thinking as an educational ideal,” Educational Forum, 2016,45(1): pp.7-23.

[3] J.R.Taylor, Linguistic Categorization: Prototypes in Linguistic Theory. London: Longman, 1999.

[4] A. Byrne, “Color and the Mind-Body Problem,” Dialectica, 2006, (60): pp.223-244.

[5] V. Evans and M. Green, Cognitive Linguistics: An Introduction. Edinburgh: Edinburgh University Press, 2005.

[6] C. Harrison, Cognitive Grammar in Literature. Amsterdam/Philadelphia: John Benjamins Publishing Company, 2014

[7] R. Langacker, Cognitive Linguistics: A Basic Introduction. Oxford: Oxford University Press, 2008. 
[8] F. L. Aldama, Toward a Cognitive Theory of Narrative Acts. Texas: University of Texas Press, 2010
[9] R. Langacker, Concept, Image and Symbol: The Cognitive Base of Grammar. Berlin/ New York: Mouton de Gruyter, 1990. 